\title{
A Study on Legislation for Protection of Cultural Relics in China: Origin, Content and Model
}

\author{
Rong Chai, Hao Li \\ Beijing Normal University, Beijing, China \\ Email: na.jian g@bnu.edu.cn
}

How to cite this paper: Chai, R., \& $\mathrm{Li}, \mathrm{H}$ (2019). A Study on Legislation for Protection of Cultural Relics in China: Origin, Content and Model. Chinese Studies, 8, 132-147.

https://doi.org/10.4236/chnstd.2019.83011

Received: June 4, 2019

Accepted: August 25, 2019

Published: August 28, 2019

Copyright $\odot 2019$ by author(s) and Scientific Research Publishing Inc. This work is licensed under the Creative Commons Attribution International License (CC BY 4.0).

http://creativecommons.org/licenses/by/4.0/

\section{cc) (i) Open Access}

\begin{abstract}
Since the promulgation of the Cultural Relics Protection Law of the People's Republic of China in the last century, China's legislation on the protection of cultural relics has gradually formed a multi-level system of protection of legal sources, including the constitution, laws and regulations. After a long period of legal amendment, the content of the legislation on cultural relics protection gradually concentrates on the ownership of cultural relics, the units responsible for the protection of cultural relics, and the legal responsibilities related to the destruction of cultural relics. The focus of the origin and content of Chinese legislation on cultural relics protection determines the direction of the development of legislative model. By comparing and analyzing the theory of cultural relics legislation mode in different countries, the legislative way of cultural relics protection in China should belong to the legislative mode of coexistence of comprehensive legislation and special single legislation.
\end{abstract}

\section{Keywords}

Protection of Cultural Relics, Legal Sources, Legislative Content, Legislative Model

\section{Introduction}

"Cultural relics are relics and remains of historical, artistic, and scientific value left behind by human beings during social activities (Li, 2005)". Cultural relics protection has become a hot issue that has received wide concern around the world, so many governments and some international organizations have formulated relevant laws and regulations or international conventions to protect and rationally use cultural relics. Similarly, after the Standing Committee of the National People's Congress, one of the Chinese legislatures, enacted the Cultural Relics Protection Law of the People's Republic of China in 1982, the work of the 
legal protection of cultural relics in China continued to advance. Over the years, a legal system that consists of constitutions, laws, regulations and rules, etc., for the protection of cultural relics has been formed. Therefore, combing the "legal sources" (refers to the source of the effectiveness of the law, including the creation of law and the external manifestations of legal norms) (Zhu, 2011) of the legislation on cultural relics protection has important significance for understanding the boundaries of China's existing cultural relics protection legislation and clarifying the current legislative model for cultural relics protection in China.

\section{Combing the Statutory Institutions of Protection of Cultural Relics and Legal Sources in China}

As the source of legal protection at the highest level of cultural relics protection, China's Constitution has made a principle regulation for the protection of cultural relics. In the Basic Law formulated by the National People's Congress, in addition to the Cultural Relic Protection Law of the People's Republic of China, there are the Property Law (P.R.C.), Criminal Law (P.R.C.), Law on Administrative Penalty (P.R.C.), and The Administrative Litigation Law (P.R.C.) relating to cultural relics protection. In addition, some rules in the Contract Law (P.R.C.), Auction Law (P.R.C.), and Forestry Law (P.R.C.) also concern the protection, utilization and development of cultural relics. These laws have corresponding legal effects in regulating the legal relations of activities to protect immovable cultural relics; therefore, they are also important legal sources of immovable cultural relics protection.

Although both the Constitution (P.R.C.) and many basic laws all involve the protection of cultural relics to varying degrees, the concrete power to implement the protection of cultural relics is within the government's administrative actions. Social changes have caused a lot of problems with the protection of cultural relics. Therefore, most of the legal sources of China's relics protection legislation formulated by the government are in response to the actual issues of Chinese relics protection, such as administrative regulations, departmental rules, local regulations, and local rules.

The administrative regulations for the protection of cultural relics refer to the legal documents concerning the administration of the country formulated by the State Council within its own power. These regulations' purpose is to implement the constitution and the law, and the former's effectiveness is second only to that of the latter two. The administrative regulations related to the legal protection of cultural relics in China include the Regulation for the Implementation of the Cultural Relic Protection Law (P.R.C.) promulgated and implemented in 2003, the Regulation on the Protection of Great Wall (P.R.C.) of 2006, and the Historical and Cultural Cities, Famous Towns, Famous Villages Protection Regulations (P.R.C.) of 2008.

The departmental rules related to cultural relics protection are mainly formulated by the departments established by the Ministry of Culture, the Ministry of 
Development and other institutions of the State Council in accordance with the law and the administrative regulations, decisions and orders of the State Council within the scope of its authority, to protect and manage immovable cultural relics. They mainly include the Interim Provisions on Administrative Penalty Procedures Relating to Cultural Relics (P.R.C.) formulated by the State Administration of Cultural Heritage in 2005, Interim Administrative Measures for the Recognition of Cultural Relics (P.R.C.) of 2009, Archaeological Excavation Management Measures (P.R.C.) of 1998, and the Administrative Measures for the Protection of World Culture Heritages (P.R.C.) of 2006. There are also the Preparation Requirements for the Protection of Historical and Cultural Cities (P.R.C.), which were jointly enacted by the Ministry of Development and the State Administration of Cultural Heritage in 1994; the Measures for the Administration of City Purple Lines (P.R.C.) enacted by the Ministry of Development for the protection of historical and cultural blocks and historic buildings in 2003; and the Rules for the Protection of Historical and Cultural Cities GB50357-2005 (P.R.C.) enacted by the Ministry of Development in 2005.

The local regulations refer to the legal documents formulated by the people's congresses and their standing committees in the provinces, autonomous regions and municipalities directly under the Central Government. They are the designated documents issued in the statutory jurisdiction according to the economic situation and practical needs of the region. The local regulations concerning the protection of cultural relics are even more numerous. The people's congresses and their standing committees in various provinces, autonomous regions, municipalities directly under the Central Government, as well as the relatively big cities have all established legal norms regarding the protection of immovable cultural relics in their area. The types of regulations are mainly divided into the following categories: First, the local regulations for the comprehensive protection of all immovable cultural relics in local administrative jurisdictions, including the provincial cultural relics' protection regulations, and the implementation measures of the Cultural Relic Protection Law of the People's Republic of China, such as the Measures for the implementation of the "Cultural Relic Protection Law of the People's Republic of China" in Beijing (P.R.C.), the Management Regulations of Fujian Province on the Protection of Cultural Relics (P.R.C.), the Regulations of Shaanxi Province on the Protection of Cultural Relics (P.R.C.), the Management Regulations of Guangxi Zhuang Autonomous Region on the Protection of Cultural Relics (P.R.C.), and the Management Regulations of City on the Protection of Cultural Relics (P.R.C.). Second, local regulations for a specific category of cultural relics, such as the Regulations of Sichuan Province on the Protection of World Heritage (P.R.C.), the Measures for the Protection of the Historical and Cultural Landmark of Beijing (P.R.C.), the Measures for the Protection of the Historical and Cultural Landmark of Shandong Province (P.R.C.), the Regulations of Ningxia Hui Autonomous Region on the Protection of Rock Painting (P.R.C.), the Measures for the Protection of the Historical and Cultural 
Landmark of Guangzhou Province (P.R.C.), and the Regulations of Nanjing City on the Protection of Underground Cultural Relics (P.R.C.). Third, special local regulations for specific and immovable cultural relics, such as the Regulations of Fujian Province on the Protection of one of the world's cultural heritage "Fujian Tulou" (P.R.C.), the Regulations of Gansu Province on the Protection of Dunhuang Mogao Grottoes (P.R.C.), and the Regulations of Hangzhou City on the Protection of Liangzhu Site (P.R.C.).

The local rules for the protection of cultural relics refer to the regulations formulated by the people's governments of provinces, autonomous regions, municipalities directly under the Central Government, and relatively big cities in accordance with the laws, administrative regulations, and local regulations of the province, autonomous region, and municipality directly under the Central Government. Their purpose is also to regulate the protection and management of cultural relics. For instance, the Interim Measures of Beijing Municipality for Administration of Using Protected Cultural Relic Sites to Shoot Films and Television Programmes (P.R.C.), the Management Regulations of Beijing City on the protection scope and construction control zone of Heritage Conservation Unit (P.R.C.), the Regulations of Administrative Responsibility of Shaanxi Province on Investigate of Major Cultural Relics Safety Accident (P.R.C.), the Management Regulations of Fujian Province on Protection of Cultural Relic "Fujian Tulou" (P.R.C.), and the Measures for the Protection of the Historical and Cultural Landmark of Wuxi City (P.R.C.).

The legal source of Chinese cultural relics protection legislation not only includes the internal legal system of the country but has also absorbed the beneficial experiences that have formed general international common sense in the field of cultural relics protection legislation. Among them, the most direct is the recognition and application of some international conventions for the protection of cultural relics. The international legal conventions concerning the protection of cultural relics are taken as the official legal source for the protection of cultural relics in China. And the most important international convention in the protection of cultural relics in China is the Convention Concerning the Protection of the World Cultural and Natural Heritage enacted by UNESCO in 1972. China joined the Convention in 1985 and became an important state party.

It can be seen that the legal source of China's cultural relics protection legislation has touched almost every corner of cultural relics protection from top to bottom and in different categories. According to different statutory authorities, this legislation serves as the regulation and legal effect in different hierarchies of cultural relics protection. As far as classification is concerned, its systematization and structuring are quite complete. This legislation can provide legal support for the protection of cultural relics in form. However, the concrete effect of its implementation depends on whether the setting of specific legislative content is in line with the reality of Chinese society. 


\section{Historical Changes of the Main Contents of Chinese Cultural Relics Protection Legislation}

The Cultural Relics Protection Law of the People's Republic of China promulgated in 1982 laid the foundation for Chinese legislation on the protection of cultural relics. Its main contents include the following aspects: First, the scope of protection of immovable cultural relics is clearly defined; Second, the ownership of cultural relics is clearly defined; Third, the administrative institution for the protection of cultural relics is established; Fourth, the institution of cultural relics protection units and the protection institution of Historical and Cultural Landmark Cities are improved and completed. In 2002, China's legislature carried out an important and comprehensive revision of the Law of the People's Republic of China on the Protection of Cultural Relics in order to eliminate the drawbacks of the old law that did not meet the requirements of current economic and social development. The specific contents of the amendment include: First, an expanded scope of the protection of immovable cultural relics. Whether or not there is a title of the Cultural relic protection units, all immovable cultural relics are incorporated into the scope of protection; Second, the grant of more administrative powers to the administrative authority for cultural relics protection, such as the power of administrative punishment.

Soon after, the Standing Committee of the National People's Congress revised the Law of the People's Republic of China on the Protection of Cultural Relics in a small scope in 2007 to further grant administrative relics protection authorities more administrative power. In 2013, the Standing Committee of the National People's Congress once again revised the Cultural Relic Protection Law of the People's Republic of China, reducing restrictions on the exercise of ownership of private immovable cultural relics. At the same time, Paragraph 2 of Article 25 of the Law of the People's Republic of China on the Protection of Cultural Relics was amended to read: "Where any non-state-owned unmovable cultural relics are transferred, mortgaged, or the use thereof is changed, the matter shall be submitted to the corresponding department of cultural relics administration for record according to the protection level thereof"; Paragraph 2 of Article 56 was amended to read: "Cultural relics for auction by auction enterprises shall be examined before auction by the departments of cultural relics administration of the people's governments of the provinces, autonomous regions, and municipalities directly under the Central Government, and reported to the department of cultural relics administration under the State Council for record".

In 2015, the Standing Committee of the National People's Congress decided to relax controls on cultural relics and release cultural relics with the rise of economic vitality. By amending Paragraph 2 of Article 34 of the Law of the Law of the People's Republic of China on the Protection of Cultural Relics into: "Cultural relics excavated shall be registered and appropriately kept, and be transferred to state-owned museums, libraries or other state-owned cultural relics 
collection entities designated by the cultural relics administrative departments of people's governments of provinces, autonomous regions, and municipalities directly under the Central Government, or by the cultural relics administrative department of the State Council. With the approval of the cultural relics administrative departments of people's governments of provinces, autonomous regions, and municipalities directly under the Central Government, the entities undertaking archaeological excavations may keep a small amount of unearthed cultural relics as samples for scientific research", and deleting the original scientific research sample's requirement of the approval of the "cultural relics administrative department of the State Council", gives local cultural relics research units more autonomy and convenience. "The exchange of collected Grade 1 cultural relics in museums must be subject to the approval of the cultural relics administrative department of the State Council" in Article 41 is deleted, to facilitate the legal circulation of artefacts between regional museums. In the same way, "The cultural relics administrative department of the State Council or" in Paragraph 1 of Article 53 is deleted, and "The cultural relics administrative department of the State Council" in Paragraph 1 of Article 54 is amended to read: "the cultural relics administrative departments of people's governments of provinces, autonomous regions, and municipalities directly under the Central Government" to promote the scientific development of the cultural relics market.

In 2017, the Standing Committee of the National People's Congress decided to amend a total of eleven laws, including the Cultural Relic Protection Law of the People's Republic of China. The amendments to the protection of cultural relics mainly focused on the following aspects: First, by amending Paragraph 2 of Article 20 , the demand for the protection of the original site was enhanced. If it has not been approved by the corresponding cultural relics administrative department, construction must not be started. Second, by amending Paragraph 2 of Article 40, the restrictions on the borrowing of Grade 1 cultural relics collected in a museum are reduced. This no longer requires approval. Instead, the borrowing only needs to be filed with the cultural relics administrative department of the State Council. Third, Paragraph 1 of Article 56 is amended to read: "Cultural relics shops shall not sell and auction enterprises shall not auction the cultural relics prescribed in Article 51 of this Law". The purpose of this amendment is to further enhance the vibrancy of the cultural relics shops. Fourth, Paragraph 1 of Article 57 is amended to read: "The cultural relics administrative department of the people's government of the province, autonomous region or municipality directly under the Central Government shall establish the cultural relics sale and auction information and credit management system. When a cultural relics shop purchases and sells cultural relics or an auction of enterprise auctions cultural relics, it shall make records according to the relevant provisions of the state, and within 30 days after the sale or auction of cultural relics, report it to the cultural relics administrative department of the people's government of the province, autonomous region or municipality directly under the 
Central Government for recordation". The appearance of this provision marks the development of a new, healthy cultural relics sales management system. Fifth, a paragraph is added in Article 71 as Paragraph 2: "Where a cultural relics shop or auction enterprise commits any violation of law prescribed in the preceding paragraph, the cultural relics administrative department of the people's government at or above the county level shall confiscate the illegal income and the illegally operated cultural relics, and if the amount of illegal operation is 50,000 yuan or more, it shall be fined not less than one time but not more than three times the amount of illegal operation. If the amount of illegal operation is less than 50,000 yuan, it shall be fined not less than 5000 yuan but not more than 50,000 yuan. If the circumstances are serious, the original license-issuing authority shall revoke the license". The emergence of this provision is based on the development status of the cultural relics market. The setting of the upper limit of the business value at 50,000 yuan has not been sufficient to deal with this issue, and a new ceiling has to be set to provide a legal basis.

Judging from the repeated revision of the content of the Law of the People's Republic of China on the Protection of Cultural Relics over the past few years, China's legislation on the protection of cultural relics presents a trend of expanding local government autonomy and guaranteeing gradual market activity. Of course, this trend is accompanied by regulations that are specific to the actual development of the society, but overall it is still a legal change in the law for the diversification of cultural relics protection and the rationalization of use of cultural relics. In fact, through continuous revision, China has gradually established a cultural relics protection system and framework that is closely coordinated between the central and local governments. Among them, local governments have greater autonomy, cultural relics have become more convenient, and the cultural relics market has become more standardized.

In addition to the contents of the Cultural Relic Protection Law of the People's Republic of China, other laws that do not specifically provide for the protection of cultural relics can also contain specific contents related to cultural relics protection. As stated in Article 51 of the Property Law (P.R.C.): The cultural relics that shall be owned by the state as prescribed by law belong to the state. In addition to China's existing Criminal Law, including provisions that concerning the destruction of immovable cultural relics, and theft of ancient tombs, these contents complement the criminal liabilities set out in the "Legal Responsibilities" in Chapter 7 of the Cultural Relic Protection Law of the People's Republic of China. For example, articles 64 and 67 of the Cultural Relics Protection Law of the People's Republic of China list the crimes of "wilfully or negligently damaging valuable cultural relics under state protection", "excavating sites of ancient culture or ancient tombs without permission", and the criminal liabilities that should be borne by law. There are some provisions in the Administrative Licensing Law (P.R.C.) that will affect the implementation of cultural relics protection. According to the Cultural Relic Protection Law of the People's Republic of China, a 
large number of activities which relate to immovable cultural relics require the government and cultural relics administrative departments to give administrative licenses, such as the repair of immovable cultural relics and change in the use of cultural relics. Table 1 can reflect the process of Chinese cultural relics protection legislation more intuitively.

The content of the above-mentioned national laws on the protection of cultural relics at the basic law level aims to define the basic scope of cultural relics

Table 1. Chinese cultural relics protection legislation process.

Legislature
The Standing Committee of the Fifth
National People's Congress of the
People's Republic of China
The Standing Committee of the Sevent
National People's Congress of the
People's Republic of China
The State Council
The Standing Committee of the Ninth
National Congress of the People's Re-
public of China

The State Council

The Standing Committee of the Tenth National Congress of the People's Republic of China

The Standing Committee of the Twelfth National Congress of the People's Republic of China

The State Council

The Standing Committee of the Twelfth National Congress of the People's Republic of China

The State Council

The Standing Committee of the Twelfth National Congress of the People's Republic of China

The State Council

Legislative time

Cultural relics protection laws

1982
The Cultural Relics Protection Law of the People's Republic of China

The Cultural Relics Protection Law of the People's Republic of China (1991 Amendment)

Rules for the Implementation of the Cultural Relics Protection Law of the People's Republic of China

The Cultural Relics Protection Law of the People's Republic of China (2002 Revision)

Regulation for the Implementation of the Cultural Relics Protection Law of the People's Republic of China

The Cultural Relics Protection Law of the People's Republic of China (2007 Amendment)

The Cultural Relics Protection Law of the People's Republic of China (2013 Amendment)

Regulation for the Implementation of the Cultural Relics Protection Law of the People's Republic of China (2013 Revision)

The Cultural Relics Protection Law of the People's Republic of China (2015 Amendment)

Regulation for the Implementation of the Cultural Relics Protection Law of the People's Republic of China (2016 Revision)

The Cultural Relics Protection Law of the People's Republic of China (2017 Amendment)

Regulation for the Implementation of the Cultural Relics Protection Law of the People's Republic of China (2017 Revision) 
protection legislation. Specifically, the legislation to implement the protection of cultural relics needs the coordination of the central government and the local government. According to relevant regulations in the Cultural Relic Protection Law of the People's Republic of China, the Decision of the Standing Committee of the National People's Congress on Amending Eleven Laws including the Accounting Law of the People's Republic of China, and the Regulation for the Implementation of the Cultural Relic Protection Law of the People's Republic of China, China's cultural relics administrative departments are broadly divided into two levels: the central and local levels. The central-level cultural relics administrative departments include the State Administration of Cultural Heritage, the Ministry of Housing and Urban-Rural Development, the Ministry of Environmental Protection, etc. Local-level cultural relics administrative departments are led by local governments, and the cultural relics protection department, urban planning department, and environmental protection department undertake concrete cultural relics protection work. These departments all have the power to formulate detailed rules that apply to the protection of different objects in different specific situations. Because the rules are complicated, we do not enumerate them one by one.

It can be seen that the content of China's cultural relics protection legislation can at least be said to have reached a certain scale in terms of quantity, and it can gradually exert the role of the local cultural relics administrative department and combine legislation with practice as much as possible. Moreover, the legislative content of cultural relics protection appears not only in the special basic law but also in the law governing other fields, providing a certain degree of convenience for the concrete implementation of cultural relics protection. Of course, it is accompanied by the issue of potential "Concurrence of Articles". In order to further analyse whether the current status of cultural relics protection legislation needs to be changed, the primary task is to have a clear understanding of the legislative model for cultural relics protection. The correct understanding comes from the grasp of the premise, a summary of any possible relevant experience, as well as an objective analysis and evaluation of itself. Moreover, the rule of law is a demanding thing to transplant because it is multi-faceted and it can be conceived in various ways (Husa, 2018). Therefore, the model for the protection of cultural relics in different regions must first be included in the scope of the study.

\section{Current Situation and Comments on the Legislation Mode of Cultural Relics Protection in Different Countries}

We can put the legislative model into the category of legislative technology. "The writing of any good literary work necessarily includes the two phases of conception and expression. The drafting of the law is the same, and the legislative model is equivalent to the design of legislation" (Xu, 2011). As an overview of the current situation of cultural relics protection legislation in major countries in 
the world, the legislative model for cultural relics protection mainly includes three types: the separate legislative model, the comprehensive legislative model, and the unified legislative model.

The separate legislative model refers to special legislation that is based on the elements of a single cultural relic or on the protection of a particular measure by the cultural relics. Under this mode of legislation, the scope of application of the separate laws is different, but they have the same legal effect. "In addition to various types of single-line law, there is no comprehensive legislation for the protection of multiple cultural elements or human resources, and there is no legal existence that coordinates the relationship between individual laws" (Jin, 2007). Judging from the historical development of cultural relics protection legislation, in the early days of cultural relics protection legislation, most countries generally adopted separate legislative models and focused their protection on immovable cultural relics, such as historic buildings. For example, France promulgated the Historic Building Act in 1840, the Historical Monuments Protection Act in 1887, the Historic Sites Act in 1913, and the Historical Block Protection Act in 1962, etc. (Kong, 2010). Similarly, the United States promulgated the Historic Sites Protection Act in 1906, the Historical Relics Act in 1935, the Folklore Protection Act in 1976, and the Archaeological Resource Protection Act in 1979 (Gu \& Yuan, 2005). Due to the existence of historical alternatives, overlaps, and conflicts between different single-line laws, it has been difficult to implement them, and many countries are gradually becoming aware of the flaws in this legislative model. Today, in terms of cultural relics protection legislation, many countries have turned to two other legislative models. However, a few countries with a tradition of case law, such as the United Kingdom and the United States, have yet to change their legislative model and still insist on separate legislative models. They use a comprehensive legislative model, that is, a combination of the basic law and the single-line law approach to the legislative model. The main feature of the comprehensive legislative model is to first formulate a basic law to regulate different types of issues concerning the protection of cultural relics in principle. Then, according to the different types of cultural relics or different protection measures, a number of single-line laws on the protection of cultural relics are drafted. At the same time, sub-categories can also be subdivided into different types, and a more detailed legal specification can be formulated. The main expressions are as follows: The common principles and systems in the single-line laws are summarized, on the basis of which a basic law for the protection of cultural relics that transcends the single-line laws is formulated as a guideline for cultural relics legislation, and then specific rules for the protection of cultural relics are formulated in the single-line laws. "This model has its unique advantages: it can overcome the inadequacies of the single-line legislative model and avoid the rigidity of the code legislative model" (Zhang, 2008)" Japan and South Korea all adopt this legislative model. Similarly, in Taiwan Province of China, the Cultural Heritage Preservation Act is the basic law, and single-line laws were formulated, such as the Local Government Act, the 
Land Act, the Urban Planning Law, the Regional Plan Act, the National Park Law, the Urban Renewal Act, the Building Act, etc. Taiwan, Province of China also has local regulations, such as the Taipei city monuments and monuments set the operating point, the Taipei City Management and Maintenance of historic sites, the Hsinchu City, monuments review and evaluation of the main points of operation and others, including specific enforcement regulations $(\mathrm{Xu}$, 2006).

The unified legislative model, that is, the codification of cultural relics protection issues, adjusts and regulates the affairs of the protection of cultural relics through a unified code. This model aims to compile a complete code of the legal norms of cultural relics in accordance with a certain logic system that is closely related and contains almost no repeated words. This kind of legislative model is mainly used by countries with statutory traditions to integrate and reform the national mature legal system for cultural relics protection and formulate a code for the protection of cultural relics. France and Italy are typical representatives of the unified legislative model in the field of cultural relics protection legislation. France and Italy are countries with rich experience in the protection of cultural relics. At the same time, they are also countries with profound code compilation traditions and strong code circumstances. In 2004, France compiled more than 100 laws on the protection of cultural relics that had been enacted before and formed a comprehensive cultural heritage code, the French Cultural Heritage Code. The Code is divided into seven parts, covering general rules, archives, libraries, museums, archaeology, historical monuments and landscapes and protected areas, and overseas cultural heritage. It clearly stipulates the concept of different types of cultural relics, acquisition, transfer, preservation, restoration and punishment of illegal acts (Wang, 2012). Similarly, Italy established the Cultural and Landscape Heritage Code in 2004. The law integrates general principles, cultural property, landscape property and penalties, covering almost all aspects of cultural relics protection. It absorbs the laws of the previous cultural relics and the protection of natural heritage. It is a master of Italian cultural heritage protection law. Thus, it can be seen that France and Italy have added, deleted, modified, merged, and rearranged chapters on the basis of the existing one-way law, and have been integrated into a comprehensive code with a wider range of adjustments. The biggest advantage of this legislative model is its evenness in search and retrieval.

From the perspective of changes in the selection of cultural relics protection legislation in various countries of the world, different cultural relics protection legislation models apply to different local resources. Although there is no distinction between the advantages and disadvantages of cultural relics protection legislation, there are differences between the applicable and inapplicable ones. The separate legislative models were widely used at the beginning of cultural relics protection legislation, but could only take root in those countries that originally had a tradition of case law. Countries that have statutory traditions will eventually move toward a unified legislative model even if early cultural relics 
protection legislation adopted separate legislative models. The comprehensive legislation model is applicable to countries where the characteristics of domestic cultural relics protection are diverse and complex. Therefore, what kind of cultural relics protection legislation model China chooses needs to consider the actual needs of China's cultural relics protection. Because China has a long history and many ethnic groups, a unified legislative model will not only increase unnecessary costs, but also curb the vitality of cultural relics protection. However, the use of separate legislative models may lead to too many laws and waste of resources. The comprehensive legislation model is a feasible choice for the protection of cultural relics in China at this phase. At the same time, in order to emphasize the particularity of some cultural relics' protection, special legislation is needed. Therefore, China's cultural relics protection legislation can be called a legislative model that includes a comprehensive legislative model and a special legislative model.

\section{An Analysis of the Legislation Mode of China's Cultural Relics Protection: Comprehensive Law and Special Legislation Model Coexist}

The legal norms related to the protection of cultural relics in China have a greater degree of legal effects, ranging from the Constitution with the highest level of legal effects in China, down to other normative documents related to cultural relics protection. Their contents include archaeological excavations, cultural relics protection units, collections and cultural relics management, cultural relics appraisal, cultural relics removal, security, professional titles, cultural relics shops, property audits, historical and cultural landmark cities and other aspects. A multi-grade and multi-level legal system for cultural relics protection has been preliminarily formed and based on the constitution and the Cultural Relic Protection Law of the People's Republic of China, and has a number of single-line legal norms (Liang \& Gu, 1988).

The most important comprehensive law in the field of Chinese cultural relics protection legislation is the Cultural Relic Protection Law of the People's Republic of China, which sets out the principles for the protection of Chinese cultural relics. In order to solve the operational problems of different types of cultural relics protection issues, state agencies at different levels have formulated a series of more detailed comprehensive legal norms, as well as single-line legal norms for different types of cultural relics or concrete protective measures.

The number of single-line methods in the field of Chinese cultural relics protection legislation is huge and the structure is complicated. These methods include individual legislation for a certain type of cultural relics. The Historical and Cultural Cities, Famous Towns, Famous Villages Protection Regulations (P.R.C.) of 2008, the Regulations of the People's Republic of China Concerning the Administration of the Work for Protection of Underwater Cultural Relics 
(P.R.C.) of 1989, the Regulations on Protection of Traditional Arts and Crafts (P.R.C.) of 1997 were formulated by the State Council. T State Administration of Cultural Heritage promulgated the Regulations on the Management of Ancient Human Fossils and Ancient Vertebrate Fossils (P.R.C.) in 2008 and the Administrative Measures for the Protection of World Culture Heritages (P.R.C.) in 2006. There are also the Measures for the Administration of City Purple Lines (P.R.C.) of 2003 and the Rules for the Protection of Historical and Cultural Cities GB50357-2005 (P.R.C.) enacted by the Ministry of Development in 2005. At last, there is the Preparation Requirements for the Protection of Historical and Cultural Cities (P.R.C.), which was jointly enacted by the Ministry of Development and the State Administration of Cultural Heritage in 1994, etc. These methods also include individual legislation for a concrete cultural relics, such as the Regulation on the Protection of Great Wall (P.R.C.) formulated by the State Council in 2006, the Regulations of Gansu Province on the Protection of Dunhuang Mogao Grottoes (P.R.C.) formulated by the Standing Committee of the People's Congress of Gansu Province in 2002, and the Measures for the Protection of the Third Lane, Seven Lanes and Zhu Zifang Historical and Cultural Blocks in Fuzhou (P.R.C.) formulated by the People's Government of Fuzhou of Fujian Province in 2006. Similarly, methods used include a single-line law on a concrete protection measure, such as the Interim Administrative Measures for the Recognition of Cultural Relics (P.R.C.) of 2009, the Interim Provisions on Administrative Penalty Procedures Relating to Cultural Relics (P.R.C.) of 2005, and the Archaeological Excavation Management Measures (P.R.C.) of 1998, which were formulated by the State Administration of Cultural Heritage. Finally, these methods also include other "normative documents" (Normative documents are a unique legal system or legal phenomenon in China. The normative documents we have studied are narrowly defined documents with effects below the rules. The narrowly-defined normative document, commonly known as the "red-headed document", is the most important category of various types of documents formulated and issued by organs, organizations, and organizations at all levels. The existence of such normative documents has important value and significance for the implementation of laws, regulations and rules) (Zhang, 2017) that have the least legal effect, such as the Management Measures for Special Funds for Protection of Large Sites (P.R.C.) and the Cultural Heritage System Museum Risk Rating and Security Protection Level Regulations (P.R.C.) of 2008, etc.

Table 2 and Table 3 more intuitively reflect the current situation of the legislative model of China's cultural relics protection legislation:

\section{Conclusion}

Cultural relics protection is a common topic among all of human society. Since the industrial revolution, with the increasing trend of global integration, both cultural relics and intangible cultural heritage have been seriously threatened. In 
Table 2. China's comprehensive cultural relic protection legal norms system.

\begin{tabular}{|c|c|}
\hline & Comprehensive cultural relics protection laws \\
\hline Law & Law of the People's Republic of China on the Protection of Cultural Relics (1982) \\
\hline \multirow{2}{*}{ Administrative regulations } & $\begin{array}{l}\text { Rules for the Implementation of the Law of the People's Republic of China on the Protection of Cultural } \\
\text { Relics (1992) }\end{array}$ \\
\hline & $\begin{array}{l}\text { Regulation for the Implementation of the Law of the People's Republic of China on the Protection of } \\
\text { Cultural Relics (2003) }\end{array}$ \\
\hline \multirow[t]{2}{*}{ Local regulations } & $\begin{array}{l}\text { Measures for the implementation of the "Cultural Relic Protection Law of the People's Republic of China" } \\
\text { in Beijing (P.R.C.) (2004) }\end{array}$ \\
\hline & Regulations of Shaanxi Province on the Protection of Cultural Relics (P.R.C.) (2006) \\
\hline
\end{tabular}

Table 3. China's single cultural relics protection legal norms system.

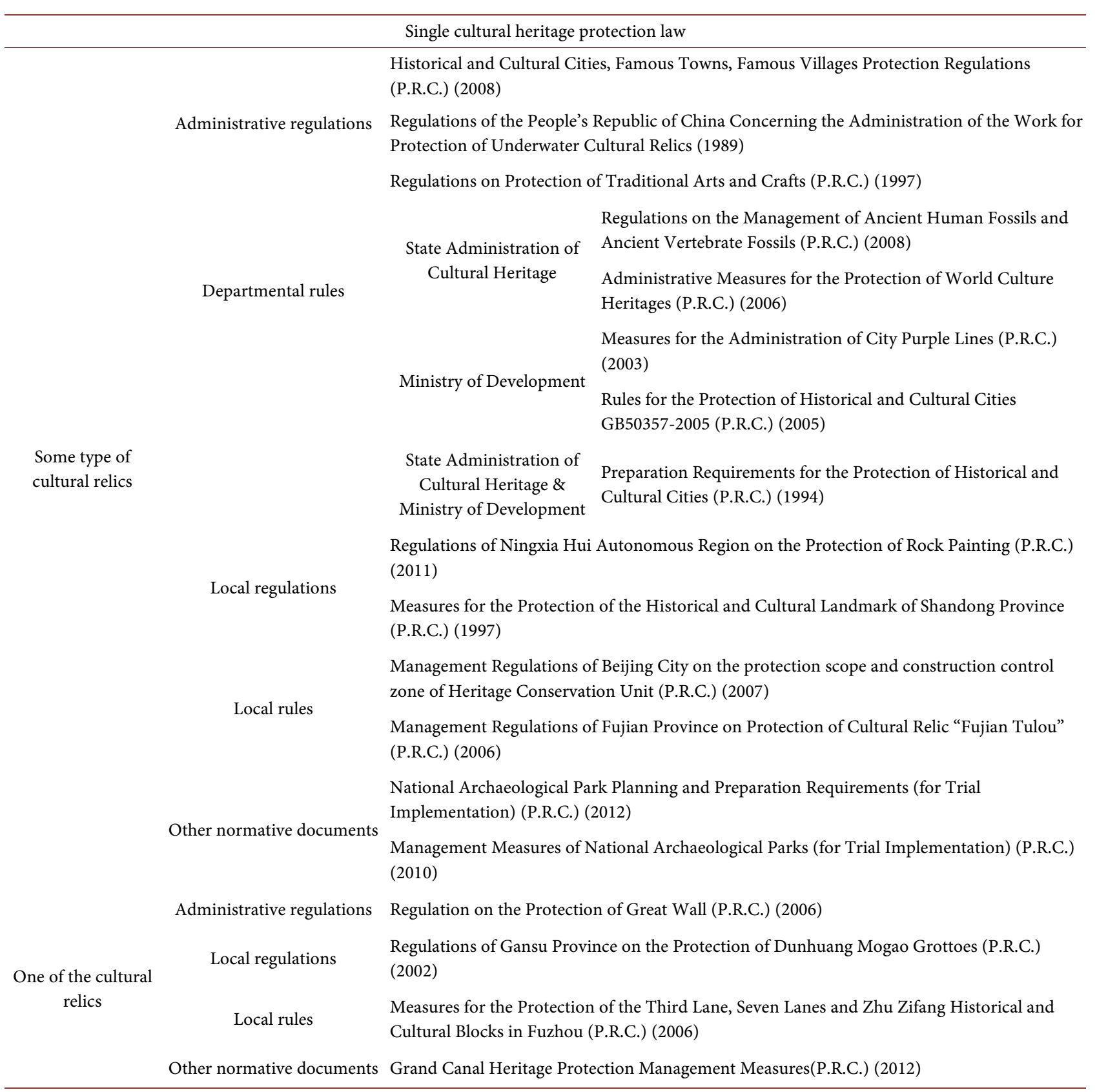




\section{Continued}

\begin{tabular}{lll}
\hline & Interim Administrative Measures for the Recognition of Cultural Relics (P.R.C.) (2009) \\
& Departmental rules & $\begin{array}{l}\text { Interim Provisions on Administrative Penalty Procedures Relating to Cultural Relics (P.R.C.) } \\
(2005)\end{array}$ \\
& Archaeological Excavation Management Measures (P.R.C.) (1998) \\
& Interim Measures of Beijing Municipality for Administration of Using Protected Cultural \\
& Relic Sites to Shoot Films and Television Programmes (P.R.C.) (2001) \\
One of the concrete & Regulations of Administrative Responsibility of Shanxi Province on Investigate of Major \\
protection measure & Cultural Relics Safety Accident (P.R.C.) (2012) \\
& State Administration of Cultural Heritage Key Research Base Operation Evaluation Rules \\
& (P.R.C.) (2008) \\
& $\begin{array}{l}\text { Measures for the Administration of Qualification of Supervision and Administration over } \\
\text { Cultural Relic Protection Projects (for Trial Implementation) (2014) }\end{array}$ \\
& $\begin{array}{l}\text { Grading Standards for Collections of Cultural Relics at the Modern and Modern Level (for } \\
\text { Trial Implementation) (2007) }\end{array}$ \\
&
\end{tabular}

order to retain this endangered and important historical and cultural resource, cultural relics are increasingly valued by governments and international organizations. The protection of cultural heritage through the formulation of laws has become one of the most effective ways for countries and regional organizations to manage cultural relics. Therefore, it is of far-reaching significance and importance to attach importance to the establishment of a system for the protection of cultural relics. China is an ancient and large country of culture and occupies an important position in the global movement for the protection of cultural relics. It has been remarkably successful in integrating into the existing international governance orders with a growing ability to influence the global governance architecture (Slawotsky, 2018). While constantly improving the legislative system for cultural relics protection, the unique cultural relics protection legislation produced to protect China's rich and varied cultural relics should provide a certain amount of experience in the protection of the world's cultural relics. The proposal of "cultural diversity" ${ }^{1}$ is not only a further in-depth international background for China's cultural relics protection legislation but also strong evidence of China's cultural relics protection legislation to enter a global perspective. It is believed that the deepening of the theoretical exchange of international cultural heritage protection can provide an endless life for the development of the legislative protection of cultural relics in various countries.

\section{Conflicts of Interest}

The authors declare no conflicts of interest regarding the publication of this paper.

${ }^{1}$ Cultural diversity means that human spiritual wealth and material wealth do not exist in a single form at different times and in different spaces, but present various forms. "Cultural diversity" has become a broad consensus of the international community. UNESCO adopted two important conventions on the protection of cultural diversity in the early 21st century, Universal Declaration on Cultural Diversity and Protection and Promotion of Diversity of Cultural Expressions. The two conventions clearly stated that cultural diversity has a great role in promoting the sustainable development of human society. 


\section{References}

Gu, J., \& Yuan, L. (2005). 美国文化及自然遗产保护的历史与经验 [The History and Experience of the Protection of American Culture and Natural Heritage]. Northwestern Journal of Ethnology, 3, 167-176.

Husa, J. (2018). Developing Legal System, Legal Transplants, and Path Dependence: Reflections on the Rule of law. The Chinese Journal of Comparative Law, 6, 130. https://doi.org/10.1093/cjcl/cxy008

Jin, H. (2007). 基本法模式: 我国环境立法的理性选择 [Basic Law Model: Rational Choice of Environmental Legislation in China]. Jianghuai Tribune, 5, 61-67.

Kong, D. (2010). 法国文化遗产法研究 [Research on French Cultural Heritage Law]. Ph.D. Thesis, Beijing: Zhongguo Renmin University.

Li, X. D. (2005). 文物学 [Cultural Relics]. Beijing: Xueyuan Press.

Liang, J. S., \& Gu, B. P. (1988). 新中国文物立法的回顾与展望 [Review and Prospect of Cultural Relics Legislation in China]. Chinese Museum, 4, 75-81.

Slawotsky, J. (2018). The National Security Exception in US-China FDI and Trade: Lessons from Delaware Corporate Law. The Chinese Journal of Comparative Law, 6, 245. https://doi.org/10.1093/cjcl/cxy012

Wang, Y. X. (2012). 文化遗产法教程 [Course on Cultural Heritage Law]. Beijing: The Commercial Press.

Xu, X. H. (2011). 立法学教程 [Legislation Course]. Shanghai: Shanghai Jiao Tong University Press.

Xu, Y. D. (2006). 文化宪法与文化国 [Cultural Constitution and Cultural State]. Taipei: Angle Press.

Zhang, J. (2017). 规范性文件管理制度研究 [Research on Normative Document Management System]. Beijing: Law Press China.

Zhang, Y. S. (2008). 我国环境立法模式选择辨析 [Analysis on the Choice of Environmental Legislation Model in China]. Journal of Guangdong Institute of Public Administration, 6, 54-58.

Zhu, J. W. (2011). 法理学 [Jurisprudence]. Beijing: China Renmin University Press. 